\title{
CONTRIBUIÇÃO À GEOLOGIA DO MUNICÍPIO DE CERQUILHO, SP
}

\author{
Marcos MASSOLI* \\ Anna Artemísia B. de AZEVEDO* \\ Geraldo Hideo ODA* \\ Jair SANTORO* \\ Lídia Keiko TOMINAGA* \\ Setembrino PETRI*
}

\section{RESUMO}

O município de Cerquilho situa-se na porção centro-leste do Estado de São Paulo, com uma superfície de $125 \mathrm{~km}^{2}$. Geologicamente ele é constituído pelas formações Itararé, Tatuí e Irati, bem como por intrusivas básicas e depósitos aluvionares recentes.

Este trabalho teve como objetivo o mapeamento geológico do município, na escala 1:50.000, a fim de se obterem subsídios para a identificação de áreas mais favoráveis à perfuração de poços profundos para captação de água subterrânea, com o propósito de se tentar solucionar o problema de abastecimento de água da população urbana.

A unidade geológica mais representativa é a Formação Itararé, tanto em extensão como em espessura. Sua complexa variabilidade litológica inclui principalmente diamictitos, arenitos e siltitos que se interdigitam, além de camadas de carvão na parte superior.

Sobreposta à Formação Itararé ocorre a Formação Tatuí, representada por siltitos marrons com intercalações de arenitos finos e níveis carbonáticos, atingindo espessura máxima de $60 \mathrm{~m}$.

O Grupo Passa Dois, representado unicamente pela Formação Irati, possui ocorrência limitada à parte noroeste da área. Representa-se por folhelhos acinzentados e sílex pertencentes ao Membro Taquaral, com cerca de $15 \mathrm{~m}$ de espessura, superpostos por solo avermelhado, argiloso, com sílex, atribuído como sendo manto de alteração do Membro Assistência. A espessura do Irati atinge cerca de 30m.

As intrusivas básicas ocorrem na forma de sills e diques principalmente na porção noroeste da área, junto ao rio Sorocaba.

Os depósitos aluvionares recentes, representados por sedimentos essencialmente arenosos, ocorrem nas planícies de inundação do rio Sorocaba e seus principais afluentes.

Os resultados obtidos com o mapeamento geológico associados àqueles fornecidos pela Geofísica, através de sondagens elétricas, mostram que a Formação Itararé apresenta condições mais favoráveis à existência de aqüiferos a sudeste de Cerquilho, onde ocorre a maior predominância de sedimentos arenosos.

\section{ABSTRACT}

This paper is a contribution to the geology of the Cerquilho county $\left(125 \mathrm{~km}^{2}\right)$, state of São Paulo, Brazil, which is located at the center-east of the state, $160 \mathrm{~km}$ from the city of São Paulo.

The main purpose of this research was to get geologic and lithologic maps of the area, at a 1:50.000 scale, as a contribution to a better understanding of ground water distribution. Water from wells is urgently needed to the municipality supply.

Late Carboniferous to Permian 550m thick Itarare Formation is the main stratigraphic unity in extension and in thickness. Less developed are the Permian Tatui and Irati formations. Latest Jurassic to Earliest Cretaceous tholeitic diabase intrusions, as dyke and sills cut these formations. Along some of the river valleys developed narrow alluvial deposits.

The main lithologies of the Itarare Formation are diamictites (some true tillites), sandstones and siltstones. They are highly variable in distribution, interfengering each other vertically and horizontally. Coal seams are distributed mostly in the upper beds of this formation.

* Instituto Geológico - SMA - Caixa Postal 8772 - 01051 - São Paulo, SP - Brasil. 
The $60 \mathrm{~m}$ thick Tatui Formation resting on the Itararé, is made up of brown variegated siltstones and some fine sandstones with less developed carbonate levels.

The $30 \mathrm{~m}$ thick Irati Formation stretches at the northwestern limit of the map. It is made up of grayish shales and sílex concretions.

The intrusions are present mainly at the northwest, near the Sorocaba river.

The recent alluvial deposits are essentially sandy developed in flood plains connected with the Sorocaba river drainage system.

The maps and electric profiles point to an area southeast of the Cerquilho town as richer in sandy sediments which may favour ground water accumulation.

\section{INTRODUÇÃO}

Este trabalho apresenta os resultados obtidos com o mapeamento geológico do município de Cerquilho, realizado pelo Instituto Geológico em face da solicitação da Prefeitura local. Esta manifestou a necessidade de reconhecer áreas favoráveis à perfuração de poços profundos a fim de suprir a carência de água para o abastecimento urbano.

O município de Cerquilho situa-se a cerca de $160 \mathrm{~km}$ de São Paulo, compreendendo uma área de aproximadamente $125 \mathrm{~km}^{2}$ (Fig. 1). Tem como principal acesso a rodovia Castelo Branco.

$\mathrm{Na}$ região predominam os sedimentos do Grupo Tubarão (formações Itararé e Tatuí), ocorrendo secundariamente a Formação Irati, intrusivas básicas e sedimentos aluvionares recentes.

Embora inúmeros trabalhos tenham enfocado a complexidade estratigráfica do Grupo Tubarão (SOARES et alii, 1977; IPT, 1981; PETRI \& FÚLFARO, 1983; entre outros) esta pesquisa não teve por objetivo estabelecer uma subdivisão estratigráfica da unidade, mas elaborar os mapas geológico (Fig. 1) e litológico (Fig. 2) da área, ambos na escala 1:50.000. Neste último procurou-se delimitar e caracterizar os litossomas componentes das unidades presentes, além de determinar seu posicionamento estratigráfico, com a finalidade de obter informações sobre a geometria dos corpos litológicos que possam constituir importantes aqüíferos.

\section{METODOLOGIA}

A pesquisa bibliográfica concentrouse nos principais trabalhos referentes ao Grupo Tubarão no Estado de São Paulo, bem como naqueles que se referem mais especificamente ao carvão que ocorre na área.

Utilizando-se fotos aéreas de escala
1:25.000 do IBC-GERCA, de 1972, executou-se a fotointerpretação da área, através da qual se obtiveram o traçado da rede de drenagem e os principais elementos estruturais, além do mapa fotogeológico preliminar que serviram de base para a etapa de campo.

No levantamento geológico, utilizaram-se cartas topográficas do IBGE, editadas em 1970, correspondentes às quadrículas de Porto Feliz e Laranjal Paulista. Foram percorridas todas as vias de acesso e alguns trechos das principais drenagens para descrição de afloramentos e coleta de amostras. Para a determinação da posição estratigráfica das litologias encontradas construíramse seções colunares e geológicas. Em áreas pobres de afloramentos, realizaram-se sondagens a trado manual para a identificação do tipo de rocha subaflorante, com a execução de análises granulométricas nas amostras coletadas.

Após o levantamento geológico foi selecionada uma área a sudeste da cidade de Cerquilho, onde uma equipe do Instituto de Pesquisas Tecnológicas executou um levantamento geofísico, do qual constou a realização de sondagens elétricas a fim de se verificar a variação litológica da Formação Itararé em subsuperfície (IPT, 1986).

\section{GEOLOGIA REGIONAL}

O município de Cerquilho situa-se na porção centro-leste da Bacia Sedimentar do Paraná, unidade geotectônica preenchida por sedimentos que datam desde o Paleozóico até o Cretáceo, além de incluir rochas ígneas de caráter intrusivo e extrusivo.

Dentre as unidades geológicas que compõem a bacia, merecem destaque o Grupo Passa Dois e, principalmente, o Tubarão, por constituírem o quadro geológico da área mapeada. Para ambos foi adotada a subdivisão estratigráfica 


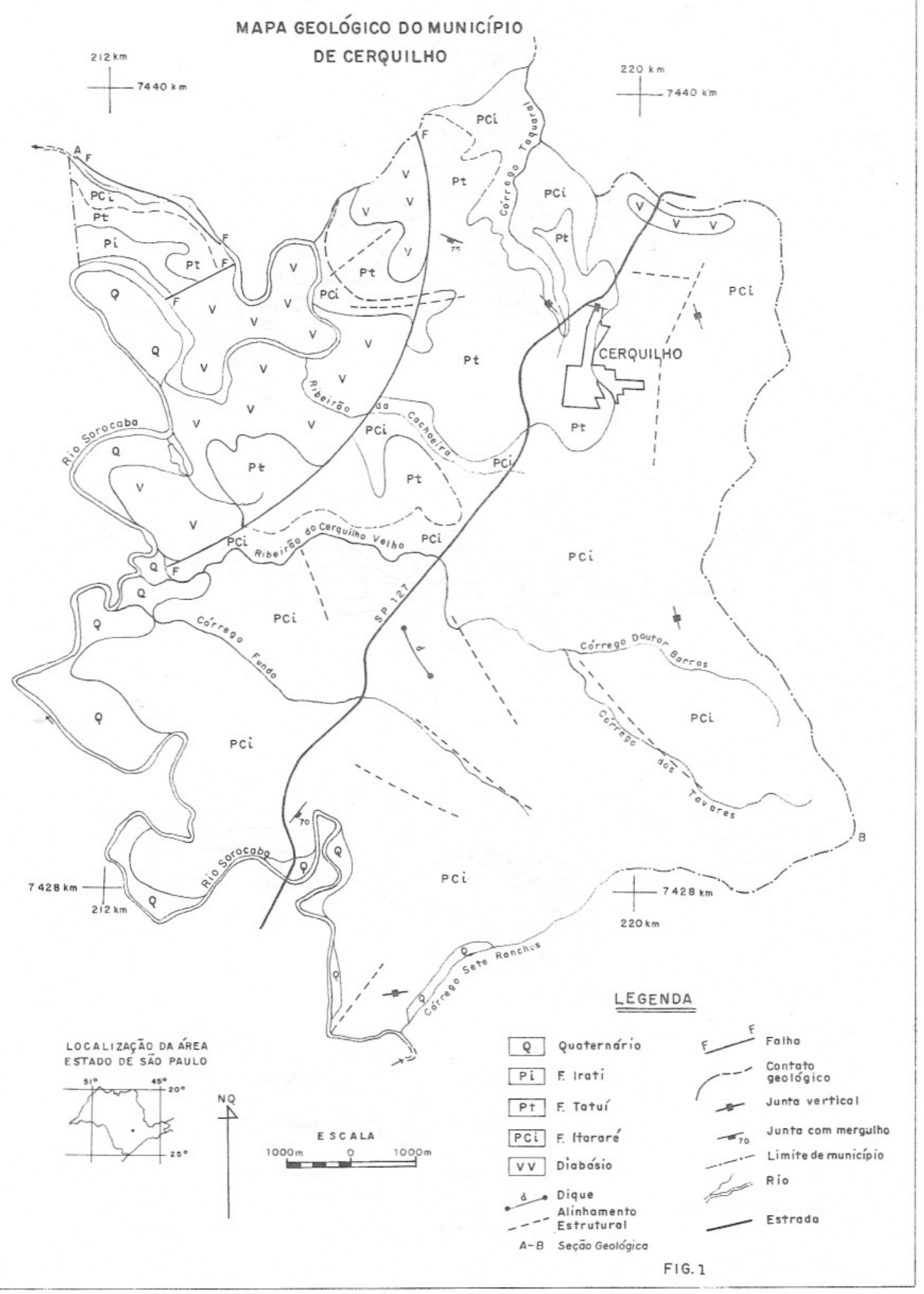




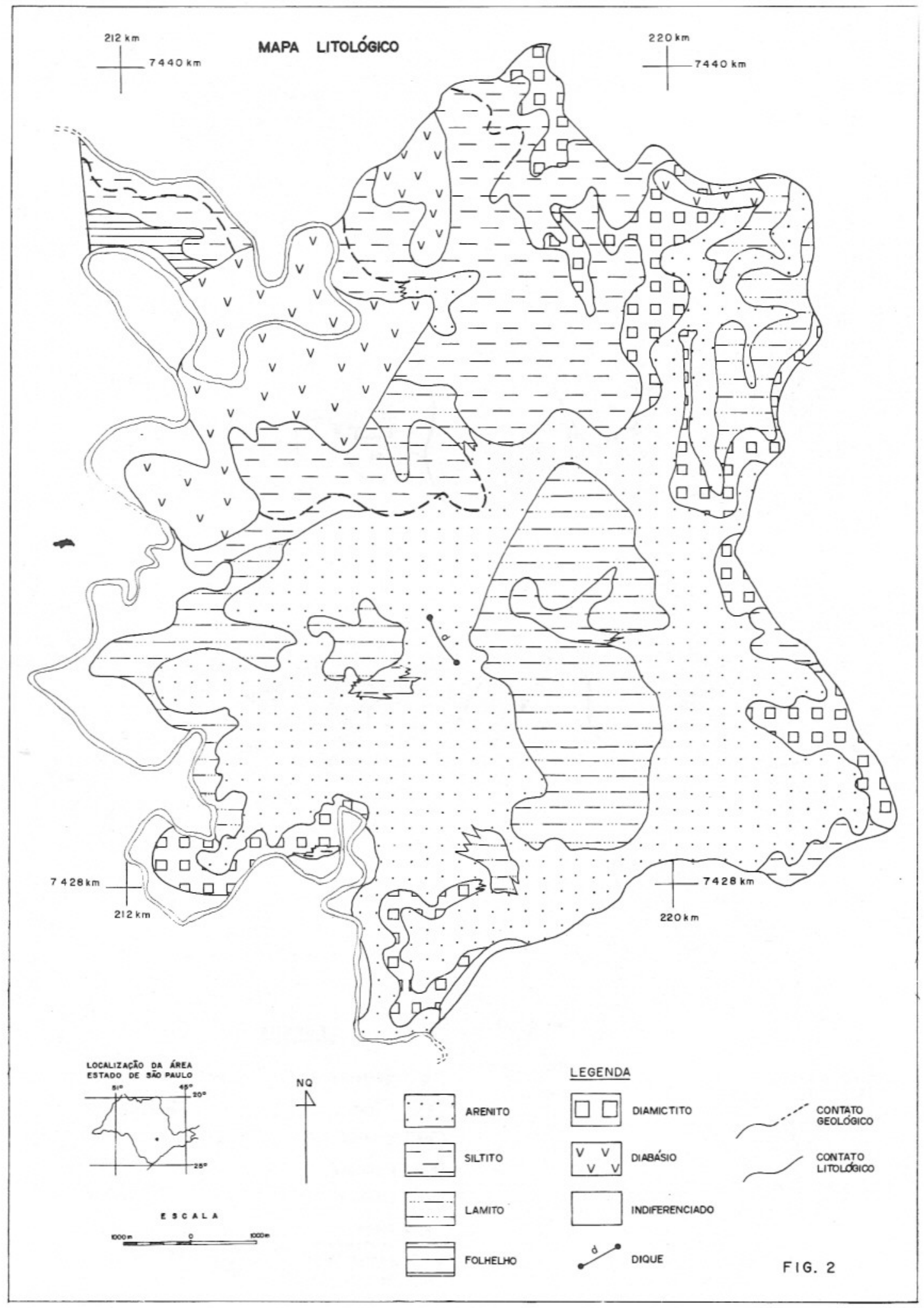


utilizada pelo IPT (1981): Grupo Tubarão, representado pelas formações Itararé/Aquidauana e Tatuí; Grupo Passa Dois, composto pelas formações Irati e Corumbataí.

A Formação Itararé representa-se por um complexo de litologias que se sucedem vertical e lateralmente, representadas em ordem de freqüência por arenitos, siltitos, diamictitos, ritmitos e argilitos, com ocorrências locais de carvão e calcário em sua porção superior. Essa complexidade litológica não permitiu ainda a subdivisão estratigráfica da unidade, embora várias tentativas tenham sido feitas (BARBOSA \& ALMEIDA, 1949; SOARES et alii, 1977; SAAD, 1977; entre outros). Essas tentativas sempre encontraram como obstáculo a inexistência de um horizonte ou associação litológica que mantivesse continuidade lateral de âmbito regional.

Sobreposta à Formação Itararé ocorre a Formação Tatuí, constituída predominantemente de siltitos. Subordinadamente ocorrem camadas de arenitos, calcários, folhelhos e sílex.

Subdivide-se a Formação Irati em dois membros: Taquaral (inferior) e Assistência (superior); no primeiro predominam argilitos, folhelhos e siltitos de cor cinza-clara e escura, podendo conter na base camada de arenito fino a grosso ou conglomerado com seixos de sílex; o Membro Assistência é constituído, principalmente, por calcários dolomitizados em alternância com folhelhos pirobetuminosos.

A Formação Corumbataí compreende siltitos, argilitos e folhelhos arroxeados, sucedidos por uma alternância de lâminas siltosas ou argilosas intercaladas a lâminas arenosas de colorações avermelhadas e arroxeadas.

\section{GEOLOGIA LOCAL}

No município de Cerquilho ocorrem as formações Itararé, Tatuí e Irati, além de intrusivas básicas e sedimentos aluvionares recentes (Fig. 1).

Dentre os trabalhos prévios realizados na região destacam-se: SOARES et alii, 1977; IPT, 1984; NAGALLI \& CONSONI, 1984; STEVEAUX et alii, 1984; FÚLFARO et alii, 1984; SOUZA F. ${ }^{\circ}, 1986$; MANIAKAS, 1986.

SOARES et alii (op. cit.) subdividi- ram a Formação Itararé nas quadrículas de Capivari, Porto Feliz e Laranjal Paulista, em membros inferior, médio e superior, sendo que na região de Cerquilho ocorreria o membro médio, caracterizado por predominância de siltitos, ritmitos e diamictitos.

Em trabalho de detalhe realizado na área de ocorrência de carvão (Bairro Aliança), IPT (1984) apresenta uma coluna estratigráfica compreendendo, a partir da base, as unidades: Formação Itararé, Formação Tatuí, Intrusivas Básicas e Quaternário. A ocorrência de carvão foi situada estratigraficamente na porção inferior da Formação Tatuí.

NAGALLI \& CONSONI (1984) situam estratigraficamente a região de Cerquilho como compreendendo a porção superior da Formação Itararé e a parte basal da Formação Tatuí. Identificaram, a partir da interpretação de perfis de sondagens, 4 unidades compostas por litofácies interpretadas como de ambientes deposicionais característicos, sendo que as unidades $\mathrm{A}, \mathrm{B}$ e C representariam o ciclo glacial (Fm. Itararé) e a unidade $\mathrm{D}$, o pós-glacial (Fm. Tatuí). Para esses autores, a camada de carvão situa-se no topo da Formação Itararé (unidade C).

Para STEVEAUX et alii (1984) o Grupo Tubarão na região de Cerquilho seria constituído de 3 unidades estratigráficas: formações Itararé, Rio Bonito e Tatuí, com o carvão situado na Formação Rio Bonito. Essa interpretação foi obtida com base em análises de perfis de sondagens, onde ocorreriam ambientes deltaicos para as formações Itararé e Rio Bonito e uma seqüência transgressiva, dominada por planície de maré e praias, para a Formação Tatuí.

FÚLFARO et alii (1984) utilizam a denominação Formação Tietê, de BARBOSA \& ALMEIDA (1949), como equivalente à Formação Rio Bonito, e a Formação Tatuí como síncrona à Formação Palermo. Para esses autores, a região de Cerquilho situa-se entre dois paleoaltos da Formação Itararé: o de Piracicaba e o de Itapetininga. Nessa área, que seria deprimida na época, ocorrem os sedimentos arenosos interpretados como fluviodeltaicos da Formação Tietê, sotopostos a siltitos e arenitos finos da Formação Tatuí, que representariam uma fase transgressiva. 
SOUZA F. ${ }^{\circ}(1986)$ subdivide o Subgrupo Itararé, na região de Campinas, em sete unidades litoestratigráficas informais: I, II, III, IV, V, VI e VII. A unidade VI compreende arenitos finos a grosseiros com marcas onduladas, secundariamente contendo diamictitos, lamitos, calcários e carvão. Corresponde à Formação Rio Bonito de STEVEAUX et alii (1984) e à Formação Tietê de FÚLFARO et alii (1984). A unidade VI encerra o carvão de Cerquilho, estando em contato transicional com a Formação Tatuí.

MANIAKAS (1986), estudando a região do baixo Rio Capivari, subdivide o Subgrupo Itararé em três unidades mapeáveis: inferior, médio e superior. A unidade inferior constituída por arenitos grosseiros, freqüentemente conglomeráticos, associados a ritmitos, sugere deposição em ambiente marinho de águas relativamente profundas com influência glacial. A unidade média compreende arenitos muito finos, argilosos, intercalados em siltitos e lamitos, e diamictitos de matriz lamítica, indicativos de ambiente marinho de águas rasas a litorâneo com influência glacial. A unidade superior é formada por arenitos, predominantemente grosseiros porém variando de finos a conglomeráticos, diamictitos síltico-arenosos e siltitos arcosianos. Seu ambiente de deposição foi interpretado como sendo fluvioglacial em planície litorânea.

\subsection{Formação Itararé}

Litologicamente constitui-se de arenitos, siltitos, diamictitos, lamitos e ritmitos de colorações creme-amareladas, avermelhadas e acinzentadas (Figs. 2 e 3). Subordinadamente ocorrem camadas de carvão e níveis carbonáticos em sua porção superior. A espessura local desta formação, em superfície, atinge cerca de $100 \mathrm{~m}$ no vale do córrego Galo de Ouro; em subsuperfície tem mais de $330 \mathrm{~m}$, conforme dados de sondagens.

Os diamictitos afloram na área mapeada (Figs. 2 e 3), ocupando cotas que variam desde $515 \mathrm{~m}$ até $600 \mathrm{~m}$. Situam-se em vários níveis estratigráficos dentro da Formação Itararé (Fig. 5) até o topo da mesma, como ocorre a oeste de Cerquilho, onde estão sobrepostos pela Formação Tatuí (Fig. 4 d). Têm cores creme- amareladas e cinzentas (pontos 11, 73, da Fig. 3). Sua matriz é predominantemente síltico-arenosa a arenosa, sendo em geral mal selecionada.

A fração psefítica dos diamictitos varia desde grânulo até matacão, predominando grânulos e seixos. No km 98 da rodovia SP-127 (Cerquilho-Rodovia Castelo Branco), ponto 11 (Fig. 3), foi encontrado um matacão de granito com cerca de $1 \mathrm{~m}$ de diâmetro, o que talvez comprove tratar-se de um verdadeiro tilito. Litologicamente os psefitos são de quartzito, arenito, granito e siltito, constituindo uma porcentagem variável da rocha, estando ora mais concentrados, ora mais dispersos. Em geral, são arredondados a subarredondadas, podendo apresentar-se também em formas facetadas e com estrias glaciais produzidas pelo movimento de geleiras (ponto 11).

A espessura dos diamictitos é variável, desde poucos metros até pelo menos uma dezena de metros, sendo difícil a sua constatação devido à descontinuidade dos seus afloramentos. No rodovia SP-127 (ponto 11) têm cerca de $12 \mathrm{~m}$ (Fig. 4 b). Em subsuperfície foram verificadas as espessuras de $40 \mathrm{~m}$ no poço $2 \mathrm{e}$ $50 \mathrm{~m}$ no poço 3 (Fig. 5), a partir das cotas $455 \mathrm{~m}$ e $410 \mathrm{~m}$, respectivamente. Esses poços estão distantes entre si cerca de $2.750 \mathrm{~m}$ (Fig. 3).

Os diamictitos apresentam estrutura maciça, embora em alguns locais, como no ponto 73 , o diaclasamento que afetou o sedimento pode dar idéia de estratificação. Nesse ponto, no leito do córrego Taquaral, ocorre um nível carbonático, de forma lenticular, com espessura de até $30 \mathrm{~cm}$. Concreções carbonáticas encontram-se no ponto 11 , com formas esferoidais, cujo diâmetro atinge até $30 \mathrm{~cm}$; veios de calcita com cristais bem desenvolvidos ocorrem preenchendo fraturas, sugerindo uma origem epigenética para as concreções, por precipitação de uma substância mineral ao redor de um núcleo. Corpos de diamictitos na forma de cunhas ocorrem como depósitos de preenchimento de fendas, verificando-se também um corpo de arenito em forma de cunha, apresentando estratificação cruzada, interpretado como sendo depositado por águas de degelo.

Os arenitos afloram predominantemente na porção centro-sul da área, como no córrego dos Tavares, córrego 


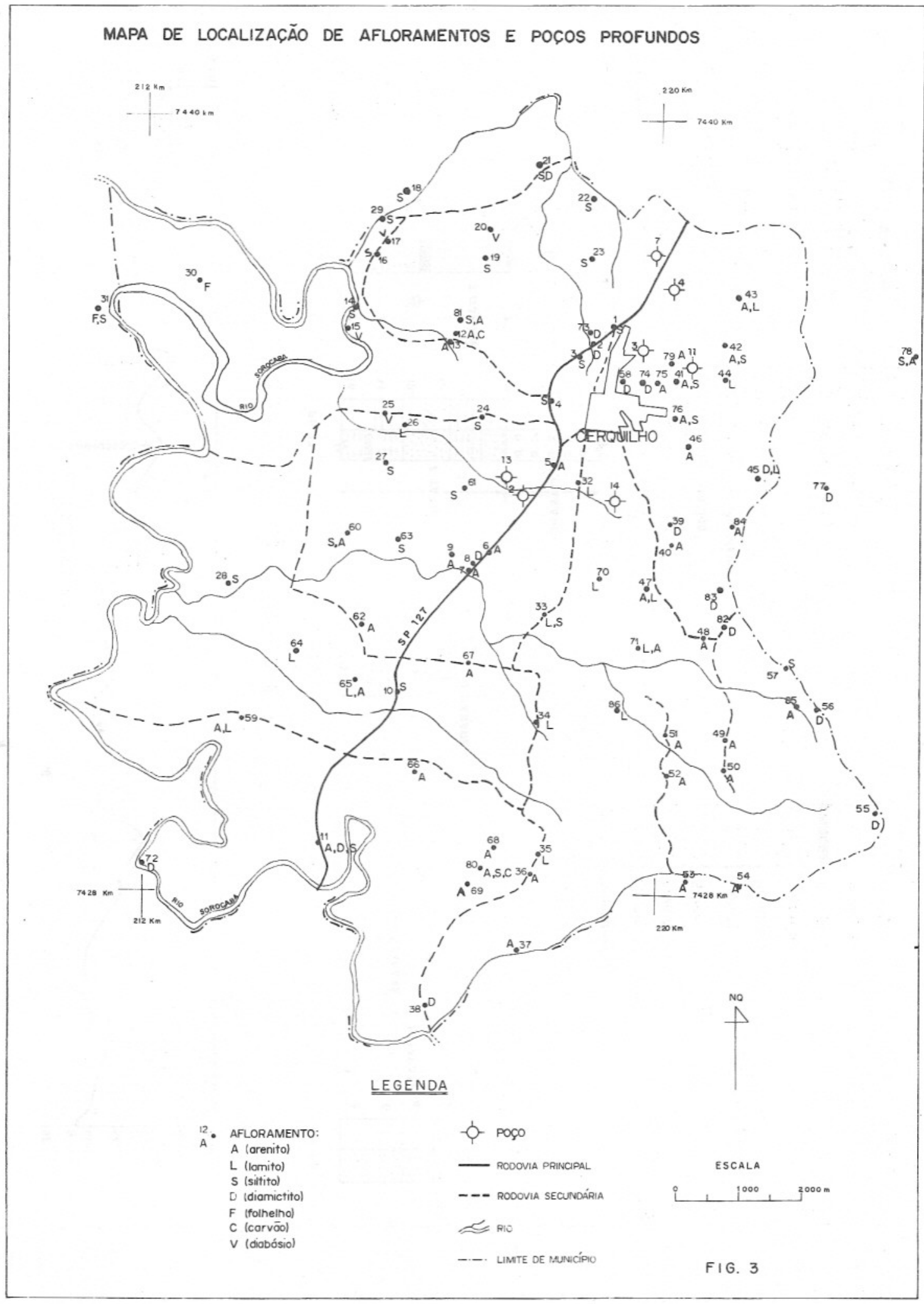




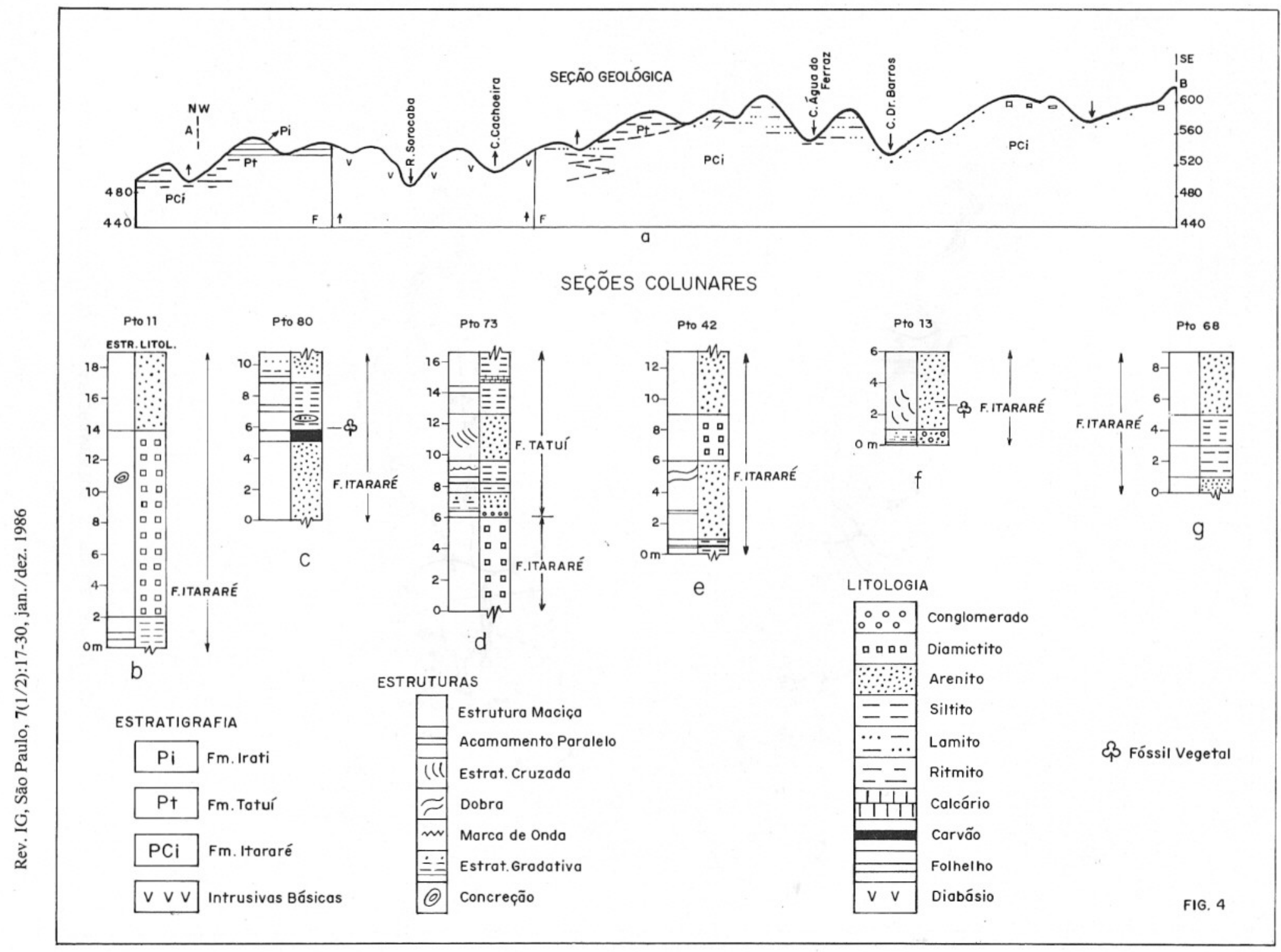




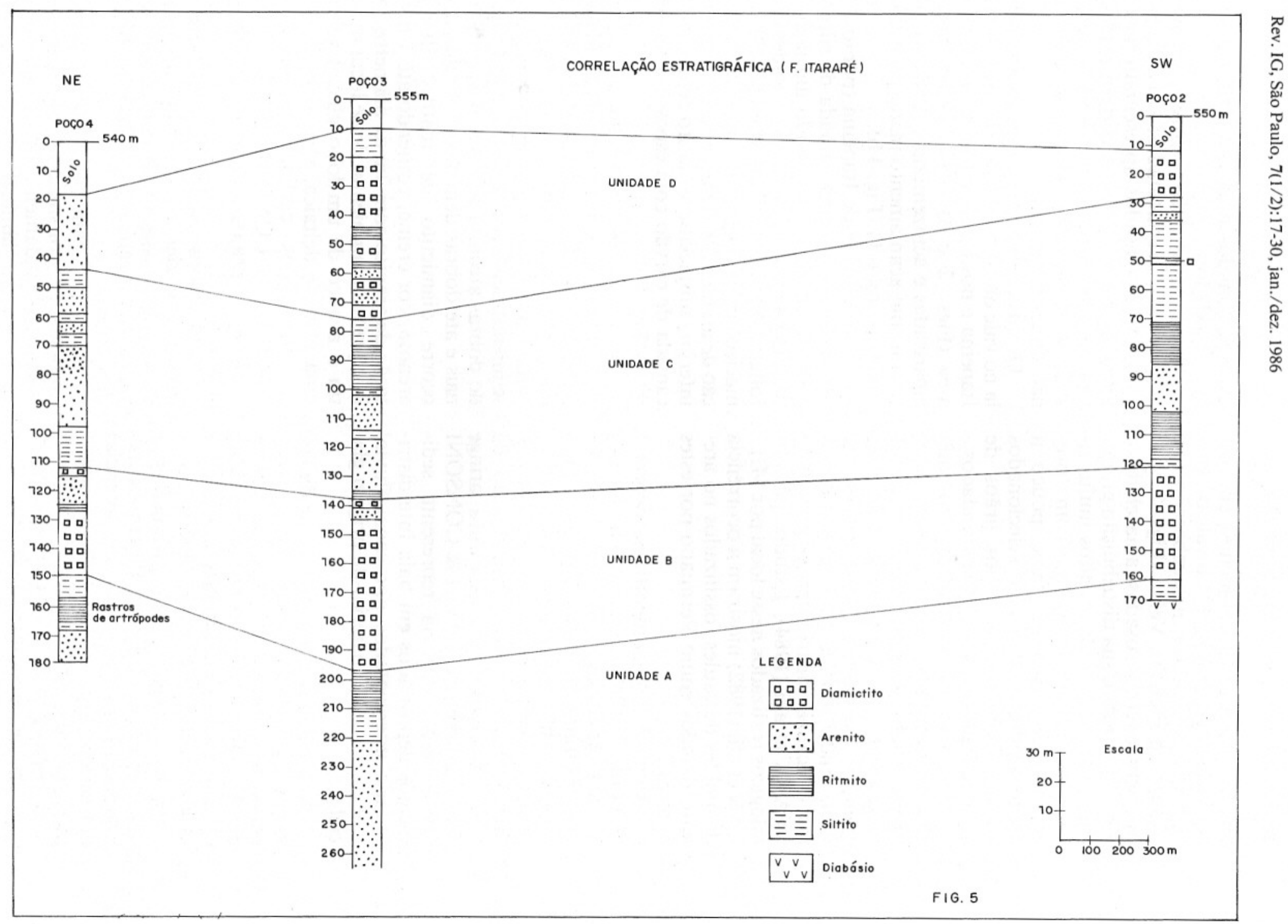


Fundo e córrego Sete Ranchos; em menor escala ocorrem junto ao vale do córrego Galo de Ouro e nas cabeceiras do córrego da Figueira Velha (Figs. 2 e 3). Apresentam cores rosadas, amareladas e esbranquiçadas e sua distribuição granulométrica varia desde arenitos muito finos até conglomeráticos, com predomínio dos arenitos finos, pouco a muito argilosos. São bem selecionados na sua fração areia, cujos grãos de quartzo mostram-se bem arredondados.

No ponto 13 ocorrem arenitos médios a grosseiros, com pouca matriz, apresentando estratificações cruzadas tangenciais e gradativas (Fig. $4 \mathrm{f}$ ); esses arenitos apresentam espessuras de até $14 \mathrm{~m}$, sendo considerados como depósitos de canais distributários por STEVEAUX et alii (1984). Estudos paleontológicos realizados nesse local por MILLAN et alii (1982) mostram a ocorrência de moldes de caules fossilizados no arenito, datados como Permiano por estes autores.

Arenitos conglomeráticos ocorrem no ponto 71 . São róseo-esbranquiçados, bastante imaturos, com intercalações de arenitos muito finos de cor creme, espessura de $5 \mathrm{~m}$, sobrepostos discordantemente a arenitos finos de cores avermelhadas, maciços, com intercalação de nível carbonoso cuja espessura atinge $5 \mathrm{~cm}$. Segundo NAGALLI \& CONSONI (1984) essa seqüência representa sedimentos depositados em baía interdistributária interceptados por canal fluvial que retrabalhou material de origem glacial.

A distribuição dos arenitos se dá em vários níveis da Formação Itararé, ocupando, em superfície, cotas que variam de $530 \mathrm{~m}$ a $600 \mathrm{~m}$. Os corpos de arenitos, de granulação fina a muito fina, dificilmente ultrapassam 30m de espessura.

A localização e dimensionamento dos litossomas arenosos é de grande importância para a avaliação do potencial hídrico da área, por apresentar a única litologia capaz de constituir um aqüífero com perspectivas favoráveis quanto à captação de água subterrânea.

Foram consideradas como lamitos as rochas que apresentam matriz síltica ou síltico-argilosa, com grãos de quartzo dispersos na mesma, sem predomínio de uma classe granulométrica representativa. Esses grãos de quartzo são, em geral, mal selecionados e arredondados a subarredondados.

Os lamitos têm cores cremeamareladas e avermelhadas; são maciços e quando diaclasados apresentam desagregação em pastilhas. Ocorrem principalmente na porção centro-sul e oestesudoeste da área (Fig. 2), com espessuras não superiores a $30 \mathrm{~m}$.

Os siltitos ocorrem em pequena escala no vale do córrego Galo de Ouro, sítio Itapema e nos extremos sul e sudeste da área (Figs. 2 e 3). Apresentam cores amareladas e acinzentadas, sendo maciços ou com acamamento plano paralelo, como no ponto 11 (Fig. 4 b).

$\mathrm{Na}$ localidade de Itapema (ponto 80 - fig. 3) ocorre uma camada de siltito creme-acinzentado, contendo um jazigo fossilífero representado por moldes de folhas (MILLAN \& DOLIANITI, 1981), maciço ou estratificado, com intercalação de arenito conglomerático na porção inferior; subjacente ao siltito ocorre uma camada de carvão com espessura de até $80 \mathrm{~cm}$ (Fig. $4 \mathrm{c}$ ).

No ponto 42 tem-se siltito de cor marrom-clara, com estratificação plano paralela, que apresenta níveis de carvão de espessuras até decimétricas. Tanto o siltito como o arenito superposto achamse intensamente perturbados, constituindo dobras atectônicas sinclinais, anticlinais e até dobras deitadas. Sobrejacente ocorre diamictito de matriz sílticoarenosa, cor creme, contendo até $1 \mathrm{ma}$ tacão de granito com $2 \mathrm{~m}$ de diâmetro. A interpretação ambiental desse local mostra o avanço de um lobo glacial sobre uma planície deltaica, representada pelos sedimentos carbonosos, segundo NAGALLI \& CONSONI (1984). A Figura $4 \mathrm{e}$, mostra o esquema desse afloramento.

A espessura máxima dos litossomas sílticos, considerando-os individualmente, não ultrapassa $20 \mathrm{~m}$ em superfície; em sondagens foram registradas espessuras de até $60 \mathrm{~m}$.

Ritmitos foram constatados apenas no ponto 68 , constituindo uma camada com aproximadamente $2 \mathrm{~m}$ de espessura, composta por lâminas de siltito esverdeado alternadas com lâminas menores de argilito marrom (Fig. $4 \mathrm{~g}$ ). Estratigraficamente situam-se cerca de $5 \mathrm{~m}$ acima da camada de carvão e do jazigo fossilífero do Sítio Itapema, na cota de $570 \mathrm{~m}$, ocupando, portanto, a porção su- 
perior da Formação Itararé. Em subsuperfície ocorrem ritmitos em vários níveis estratigráficos da formação, sendo que o mais alto verificou-se na cota de 510m (poço 3, Fig. 5) e o mais baixo na cota de $358 \mathrm{~m}$ no mesmo poço; apresentam cores acinzentadas, espessuras raramente atingindo $20 \mathrm{~m}$, contendo pistas de organismos vermiformes.

\subsection{Formação Tatuí}

Ocorre nos arredores de Cerquilho, estendendo-se para oeste e noroeste desta cidade, com espessura máxima em torno de $60 \mathrm{~m}$.

Constitui-se essencialmente por siltitos de cores amaréladas, esverdeadas e marrons, com acamamento plano paralelo e também marcas de ondas; subordinadamente ocorrem arenitos finos a muito finos róseo-esverdeados, com estratificações cruzadas ou maciços e lentes calcárias com espessuras de até $0,5 \mathrm{~m}$ (ponto 3).

A melhor exposição da Formação Tatuí verifica-se próximo ao ponto 73 , na estrada ao lado da margem esquerda do córrego Taquaral. Acima de um conglomerado interpretado como basal da Formação Tatuí, composto por seixos de quartzito e arenito, ocorrem as seguintes litologias dessa Formação: arenito fino a médio; siltito creme-amarelado, com acamamento plano paralelo e marcas onduladas; seguem-se arenitos finos, róseo-esverdeados com estratificações cruzadas, sobrepostos por siltito marrom, mostrando acamamento plano paralelo, com intercalação de camada carbonática (Fig. 4 d). O contato basal, com os diamictitos da Formação Itararé, não pode ser observado diretamente no campo por estar recoberto por material decomposto de reduzida extensão lateral e pequena espessura. De qualquer modo ficou evidenciado que a deposição da Formação Itararé, pelo menos na área estudada, terminou com os diamictitos, os quais serviram de referência para o traçado do contato entre as duas formações.

Uma ocorrência isolada de carvão, na cabeceira de um afluente da margem esquerda do córrego Taquaral, foi considerada pelo IPT (1984) como pertencente à Formação Tatuí. Neste trabalho situou-se estratigraficamente o carvão na Formação Itararé, visto que outra ocorrência carbonosa localizada em Itapema ocorre intercalada entre siltitos e arenitos, sobrepostos por ritmitos, atribuídos ao Itararé.

\subsection{Formação Irati}

Esta unidade geológica restringe-se ao extremo noroeste da área, nas proximidades do Rio Sorocaba. Compõe-se de folhelhos acinzentados e nódulos de sílex (pontos 30 e 31). Sua espessura, considerando-se o solo sobrejacente, é de no máximo $30 \mathrm{~m}$ e o contato com a Formação Tatuí se faz por brusca mudança litológica, estando esta formação representada por siltitos arenosos cremeamarelados.

A alteração das rochas da Formação Irati produz solo marrom-avermelhado, argiloso, idêntico ao regolito dos diabásios, do qual difere pela ausência de magnetita.

\subsection{Intrusivas Básicas}

Distribuem-se principalmente na porção noroeste da área, onde ocorrem sob a forma de sills de diabásio intrusivos nas formações Tatuí e Itararé (Fig. 4 a), com espessura aflorante de até $60 \mathrm{~m}$. Intrusão menor localiza-se a NNE de Cerquilho, constituindo um dique com cerca de $2 \mathrm{~km}$ de extensão e $150 \mathrm{~m}$ de largura. O poço 7 , com $186 \mathrm{~m}$ de profundidade, situado a $500 \mathrm{~m}$ a SW da intrusão, não atingiu diabásio.

O contato do diabásio com as rochas sedimentares é traçado de maneira aproximada. O regolito marromavermelhado das intrusivas básicas passa a ter tonalidades cada vez mais claras em direção aos sedimentos, além de diminuir o seu conteúdo em magnetita, existindo, assim, uma faixa de transição apresentando mistura entre os regolitos das unidades contíguas. A presença de material coluvionar, situado principalmente à meia encosta, também contribui para dificultar a delimitação desse contato.

Em subsuperfície constatou-se diabásio nos poços 13 e 14 nas profundidades de $250 \mathrm{~m}$ (cota $295 \mathrm{~m}$ ) e $215 \mathrm{~m}$ (cota $380 \mathrm{~m}$ ), com espessuras respectivamente de $40 \mathrm{~m}$ e $35 \mathrm{~m}$. No poço 11 , situado a leste de Cerquilho, ocorrem dois corpos de 
diabásio com fraturas preenchidas por calcita; situam-se nas profundidades de $10 \mathrm{~m}(\operatorname{cota} 510 \mathrm{~m})$ e $100 \mathrm{~m}(\operatorname{cota} 420 \mathrm{~m})$, com espessuras de $1 \mathrm{~m}$ e $10 \mathrm{~m}$.

\subsection{Depósitos Cenozóicos}

$\mathrm{Na}$ área mapeada ocorrem depósitos cenozóicos antigos (Terciário/Quaternário) e recentes (Quaternário).

Os sedimentos cenozóicos mais antigos são pouco expressivos, não tendo sido, por essa razão, representados no mapa geológico. Constituem depósitos arenosos com espessuras de até $3 \mathrm{~m}$, apresentando na base uma linha de seixos de quartzito, quartzo e fragmentos de limonita (pontos 33, 56, 67, 71, 83). Situamse a sudeste de Cerquilho recobrindo espigões, com altitudes em torno de $600 \mathrm{~m}$.

Os depósitos quaternários são representativos, principalmente ao longo do Rio Sorocaba, no trecho compreendido entre o Córrego Sete Ranchos (afluente da margem direita) e o Ribeirão da Onça (afluente da margem esquerda). São essencialmente arenosos, podendo conter cascalheira basal com até $2 \mathrm{~m}$ de espessura, composta por seixos de sílex e quartzito (ponto 72). Essa sedimentação foi provocada pelo represamento das águas do Rio Sorocaba na altura da Usina Santa Mária, onde a intrusão de diabásio serviu de soleira, com deposição a montante. Os depósitos da margem direita são mais extensos que os da margem esquerda.

\section{GEOLOGIA ESTRUTURAL}

Os elementos estruturais que ocorrem na área estudada são fotolineamentos, juntas e falhas.

Através da fotointerpretação identificaram-se os lineamentos representados por trechos retilíneos na rede de drenagem com persistência de pelo menos 500m (Fig. 1). Sua direção preferencial é NW, coincidindo, portanto, com os traços estruturais regionais. $\mathrm{O}$ Rio Sorocaba, embora com direção geral $\mathrm{N}-\mathrm{S}$, apresenta-se em diversos trechos segundo aquela direção preferencial.

As juntas representadas no mapa geológico foram tomadas em afloramentos, sendo verticais ou inclinadas, com direção preferencial para NW (Fig. 1). No ponto 19 ocorre um dique de diabá- sio com $0,5 \mathrm{~m}$ de largura e extensão não observável, intrusivo em siltitos da Formação Tatuí, provocando localmente arqueamento nas camadas. Essa intrusão tem direção $\mathrm{N} 65 .^{\circ} \mathrm{W}$, sendo paralela ao sistema de juntas que ocorrem no afloramento, podendo estar relacionada a falhamentos.

Evidências de um falhamento principal ocorrem no extremo noroeste da área com direção NW, correspondente a um trecho retilíneo do Rio Sorocaba, na altura da indústria Ferroligas (antiga Usina Hidrelétrica). Além do lineamento da drenagem existe o critério estratigráfico para a definição da falha, pois o contato Irati/Tatuí do lado da margem direita do Rio Sorocaba (morro do Janjão) tem altitude de $600 \mathrm{~m}$ e do lado da margem esquerda está a 540m (ponto 31), indicando uma elevação do bloco NE.

A falha inferida representada no mapa geológico (Fig. 1) tem direção NE, colocando em contato abrupto e retilíneo de um lado o diabásio (bloco SE) e do outro as formações Itararé, Tatuí e Irati (bloco NW).

$\mathrm{O}$ mergulho das camadas é de $0,3^{\circ}$ NW, conforme verifica-se na seção geológica A-B (Fig. 4 a). Para obtenção desse mergulho tomou-se como referência o contato Tatuí/Itararé que em $7.500 \mathrm{~m}$, distância entre a extremidade NW do perfil e o córrego Água do Ferraz, sofre um desnível de 40m.

\section{CORRELAÇÃO ESTRATIGRÁFICA}

Baseado em descrições de testemunhos de sondagens, procurou-se estabelecer a litoestratigrafia de subsuperfície da área estudada, com o objetivo de se definirem possíveis unidades faciológicas para a Formação Itararé, através da interpretação da seqüência evolutiva da sedimentação na região.

Para obtenção da correlação litoestratigráfica foram utilizados os perfis geológicos dos poços 2, 3 e 4 (Fig. 5), alinhados segundo a direção NE que é a direção das camadas.

Pela Fig. 5 distinguem-se 4 unidades faciológicas denominadas, da base para o topo, unidade $A$, unidade $B$, unidade $\mathrm{C}$ e unidade $\mathrm{D}$, cada uma delas composta por litofácies característica.

A unidade A, situada na parte infe- 
rior da seção estratigráfica, compreende ritmitos e siltitos de cores acinzentadas contendo rastros de artrópodes (poço 4); reflete uma sedimentação predominantemente lacustre, com paleolagos alimentados por água de degelo.

A unidade B compreende diamictitos geralmente maciços, cinzentos, matriz síltico-arenosa, com seixos até decimétricos de litologias variadas; subordinadamente ocorrem pequenas intercalações de arenitos. Sua espessura chega a $55 \mathrm{~m}$ (poço 3) e a litologia sugere água de degelo nos processos de deposição dos sedimentos.

A unidade $\mathrm{C}$ está representada por ritmitos e siltitos acinzentados, com intercalações de arenitos finos a grossos exibindo estratificação cruzada ou maciça. A espessura chega a $90 \mathrm{~m}$ (poço 3). Constitui depósitos de ambientes lacustre e fluvial formados, provavelmente, por água de degelo em planícies de lavagem.

A unidade D representa a sedimentação final da Formação Itararé, estando composta por diamictitos maciços, acinzentados e creme-amarelados, de matriz síltico-arenosa, com seixos de diâmetro e litologias variadas, tendo sido encontrado no ponto 11 um bloco de granito de $1 \mathrm{~m}$ de diâmetro; camadas de arenitos com pequenas espessuras ocorrem intercaladas, principalmente na base. Esta unidade foi observada em superfície nos pontos 11,53 e 73 , entre outros, sendo que no ponto 73 ocorre no contato com a Formação Tatuí. Com base na cota desses pontos obteve-se uma direção $\mathrm{N}$ $34^{\circ} \mathrm{E}$ e mergulho $0,5^{\circ} \mathrm{NW}$ para as camadas. Ambiente glacial teria influenciado na deposição dos sedimentos desta unidade.

\section{SEDIMENTOLOGIA}

Foram executadas análises granulométricas em 55 amostras da Formação Itararé através de pipetagem e peneiramento pelos métodos convencionais (SUGUIO 1973).

Desse total foram selecionadas 23 amostras de sedimentos arenosos com mais de $50 \%$ de areia, para caracterização da textura, uma vez que a distribuição granulométrica tem influência no comportamento hidrogeológico desses arenitos, principais rochas fornecedoras de água.

As amostras analisadas apresentam uma distribuição total média de $62 \%$ de areia, $19 \%$ de silte e $19 \%$ de argila.

Os parâmetros granulométricos da distribuição-areia forneceram os seguintes resultados:

- O diâmetro médio varia de areia fina a areia muito fina com predominância do primeiro intervalo.

- O grau de seleção situou-se entre moderadamente selecionado a bem selecionado.

- O grau de assimetria apresentou grande variação, desde positiva até muito negativa, evidenciando tendência ora para frações finas ora para frações grossas.

- A curtose, em sua maioria, apresentou-se mesocúrtica com curvas de distribuição unimodais, mostrando que não ocorre predominância de duas frações distintas (uma mais grossa ou uma mais fina) na distribuição areia.

Os arenitos não constituem bons aqüíferos devido às seguintes características: altos teores de finos (silte + argila), predominância da fração areia fina a muito fina e ocorrência em pequenas espessuras, verificadas no campo.

\section{RESULTADOS OBTIDOS E CONCLUSÕES}

1 - Os diamictitos ocorrem distribuídos por toda a área, ocupando cotas que variam de $515 \mathrm{~m}$ a $600 \mathrm{~m}$, situando-se em vários níveis estratigráficos dentro da Fm. Itararé; em subsuperfície, podem-se destacar 2 corpos de diamictitos.

2 - Arenitos pertencentes à Fm. Itararé afloram, principalmente, na porção centro-sul da área. Granulometricamente variam desde finos a conglomeráticos, com predomínio dos finos. Ocorrem com espessuras de até 30m. A Fm. Tatuí contém intercalações de arenitos finos a muito finos, com espessuras de até $2 \mathrm{~m}$.

3 - As análises granulométricas dos arenitos amostrados (exceto os conglomeráticos que são pouco representativos na área) apresentaram, em média, $62 \%$ de areia, $19 \%$ de silte e $19 \%$ de argila; diâmetro médio correspondendo à areia fina; seleção moderada a boa; grau de assimetria muito variável; quanto à 
curtose, a maioria das amostras apresentou-se mesocúrtica, com distribuição unimodal.

4 - Lamitos ocorrem na Formação Itararé principalmente na porção centrosul e oeste-sudoeste da área, com espessuras não superiores a $30 \mathrm{~m}$.

5 - Siltitos ocorrem nas Formações Tatuí e Itararé. No Itararé afloram, em pequena escala, no vale do córrego Galo de Ouro, Sítio Itapema e nos extremos sul e sudeste da área, com espessura de até $20 \mathrm{~m}$. Os siltitos da Formação Tatuí ocorrem a oeste-noroeste de Cerquilho, apresentando coloração avermelhada e esverdeada, com intercalações arenosas e carbonáticas.

6 - Ritmitos da Formação Itararé foram constatados apenas no ponto 68 constituindo uma camada de $2 \mathrm{~m}$ es- pessura. Em subsuperfície ocorrem em vários níveis estratigráficos da formação com espessuras raramente atingindo $20 \mathrm{~m}$.

7 - Sedimentos das formações Tatuí e Irati e rochas básicas ocupam o setor noroeste da área e constituem rochas de baixa permeabilidade, de interesse secundário para pesquisa de água subterrânea.

8 - O mapeamento geológico e as sondagens elétricas (IPT, 1986) indicaram a existência de maior espessura de sedimentos arenosos (cerca de 200m) na Formação Itararé, a sudeste de Cerquilho, a uma profundidade média de $250 \mathrm{~m}$. Com base nesse resultado, concluiu-se que esta área é a que apresenta condições mais favoráveis ao acúmulo de água subterrânea.

\section{REFERÊNCIAS BIBLIOGRÁFICAS}

BARBOSA, O. \& ALMEIDA, F. F. M. de 1949. A série Tubarão na Bacia do Rio Tietê, Estado de São Paulo. Rio de Janeiro, DNPM/DGM. 16 p. (Notas Preliminares e Estudos, 48).

FÚlFARO, V. J.; STEVAUX, J. C.; SOUZA FILHO, E. E.; BARCELOS, J. H. 1984 A Formação Tatuí (P) no Estado de São Paulo. In: CONGRESSO BRASILEIRO DE GEOLOGIA, 33. ${ }^{\circ}$, Rio de Janeiro, 1984. Anais. Rio de Janeiro, SBG. v. 2, p. 711-724.

IPT - INSTITUTO DE PESQUISAS TECNOLÓGICAS DO ESTADO DE SÃO PAULO. 1986 Levantamentos geofísicos aplicados à hidrogeologia na cidade de Cerquilho, São Paulo. (Relatório IPT, 23.704). 1981 Mapa geológico do Estado de São Paulo. São Paulo, v. 1. 126 p. 1984 Mapeamento geológico e estrutural de detalhe na área denominada mina de carvão em Cerquilho, SP — I fase. (Relatório IPT, 19.710).

MANIAKAS, S. 1986 Estudos geofísicos integrados à geologia da Bacia Hidrográfica do Baixo Capivari, SP. (Subgrupo Itararé e intrusivas associadas). São Paulo, IG/USP. 180 p. (Tese de Doutoramento).

MILLAN, J. H. \& DOLIANITI, E. 1981 Cordaitales do Eogondwana de Cerquilho, São Paulo (Bacia do Paraná). Anais da Academia Brasileira de Ciências, Rio de Janeiro, 53 (4):807-815.

; ; ANDRADE, A. B. 1982 Uma nova tafoflórula no Eogondwana de Cerquilho, Subgrupo Itararé de São Paulo. Anais da Academia Brasileira de Ciências, Rio de Janeiro, 54 (2): 419-428.

NAGALLI, J. T. \& CONSONI, J. O. 1984 Comportamento faciológico do intervalo que encerra as camadas de carvão, na região de Cerquilho, SP. In: CONGRESSO BRASILEIRO DE GEOLOGIA, 33. ${ }^{\circ}$, Rio de Janeiro, 1984. Anais. Rio de Janeiro, SBG. v. 2 p. 974-982.

PETRI, S. \& FÚLFARO, V. J. 1983 Geologia do Brasil. São Paulo, T. A. Queiroz, EDUSP. $631 \mathrm{p}$.

SAAD, A. R. 1977 Estratigrafia do Subgrupo Itararé no Centro e Sul do Estado de São Paulo. São Paulo, IG/USP. 107p. (Dissertação de Mestrado)

SOARES, P. C.; LANDIM, P. M. B.; SINELLI, O.; WERNICK, E.; FU-TAI, W.; FIORI, A. P. 1977 Associações litológicas do Subgrupo Itararé e sua interpretação ambiental. Revista Brasileira de Geociências, São Paulo, 7(2):131-149.

SOUZA FILHO, E. E. 1986 Mapeamento faciológico do Subgrupo Itararé na quadrícula de Campinas (SP). São Paulo, IG/USP. 121p. (Dissertação de Mestrado).

STEVEAUX, J. C.; SOUZA FILHO, E. E.; BATISTA, J. J.; PERIMOTTO, J. A. J.; LANDIM, P. M. B.; FU-TAI, W. 1984 Projeto carvão de Cerquilho. Rio Claro, Instituto de Geociências e Ciências Exatas/UNESP. v.1

SUGUIO, K. 1973 Introdução à sedimentologia. São Paulo, Edgard Blucher, EDUSP. 317p. 